\title{
PROJETO TODOS CONTRA O BULLYING: PRÁTICAS DE LEITURA E ESCRITA HIPERTEXTUAL POR ALUNOS DO ENSINO FUNDAMENTAL
}

\author{
Simone da Costa Lima* \\ Raquel Cristina de Souza e Souza*
}

\begin{abstract}
RESUMO: A ampla expansão das redes de comunicação eletrônica - a Internet - vem causando impactos profundos na sociedade, principalmente na forma com que as pessoas processam a informação e constroem o conhecimento. Como a linguagem disponibilizada no ambiente on-line é centrada na forma escrita, o conceito de texto tem sido amplamente modificado - hipertexto, hipermídia, multimídia. Em função do exposto, cabe à escola desenvolver práticas pedagógicas que atendam às demandas da sociedade atual, propiciando aos alunos a aquisição de diferentes tipos e camadas de letramento. Este trabalho relata uma experiência realizada com seis turmas de $6^{\circ}$ ano do Ensino Fundamental de uma instituição pública federal no Rio de Janeiro. Inspirado pela leitura do livro Todos contra Dante, em que o autor Luís Dill se baseia em fatos reais para criar literatura, cada aluno selecionou um caso real de bullying noticiado na mídia, criou murais on-line de recortes das notícias sobre o caso e elaborou um texto em primeira pessoa se colocando no lugar da vítima. Esse texto foi publicado em um microblog, que, assim como os murais, foi produzido com a ferramenta Padlet. Todos os trabalhos foram organizados em um ambiente do Google Sites, de forma que circulassem socialmente e cumprissem objetivos comunicativos reais. Os resultados da experiência realizada evidenciam que o uso pedagógico das TICs, além de propiciar o multiletramento dos alunos, permitiu que estes refletissem sobre um conflito real - um caso de bullying ocorrido em nossa comunidade escolar, motivação para a realização do projeto e modificassem suas atitudes no ambiente escolar.
\end{abstract}

PALAVRAS-CHAVE: Multiletramento. NTICs. Projetos de autoria.

\section{Introdução}

O desenvolvimento de Novas Tecnologias de Informação e Comunicação, doravante NTICs, propiciou a inserção dos indivíduos em novas práticas de leitura e escrita em ambiente digital sem que estas suplantassem as anteriores, pautadas no texto impresso. Do mesmo modo que a "introdução da escrita [impressa] conduziu a uma cultura letrada nos ambientes em que a escrita floresceu" (MARCUSCHI, 2005, p. 14), a introdução da escrita digital, pela sua importância, está conduzindo a uma cultura letrada digital. Sendo assim, como

\footnotetext{
*Professora de Informática Educativa do Colégio Pedro II (RJ / UFRJ), Doutoranda do Programa Interdisciplinar de Linguística Aplicada. Rio de Janeiro, Brasil. Imeio: sclmorgado@gmail.com

${ }^{* *}$ Professora de Língua Portuguesa do Colégio Pedro II (RJ / UFRJ), Doutoranda do Programa de Letras Vernáculas - Literatura Brasileira. Rio de Janeiro, Brasil. Imeio: raquelcsm@gmail.com
} 
educadores, temos dois grandes desafios: analisar o impacto que as NTICs exercem na forma com que entendemos e vivenciamos o letramento para, então, propor aos nossos alunos atividades pedagógicas que propiciem a eles a aquisição de diferentes letramentos, de modo a formar leitores que atuem em ambos os meios: o impresso e o digital.

A experiência a ser aqui relatada representa, em parte, uma iniciativa de se enfrentar esses dois desafios. Tomando como base as principais características do texto veiculado em ambiente digital, foi realizado no ano de 2013, a partir de uma parceria entre a Informática Educativa e a disciplina de Língua Portuguesa, o Projeto Todos contra o bullying. O projeto envolveu seis turmas de $6^{\circ}$ ano de uma escola pública federal no Rio de Janeiro e propiciou aos nossos alunos diferentes atividades de leitura e escrita, articulando o suporte impresso ao digital, conforme discutiremos a seguir.

\section{Práticas sociais de leitura e escrita em ambiente digital}

Com o advento da Internet, cada vez mais as pessoas têm acesso à informação e ao conhecimento por meio digital. Como a linguagem disponibilizada nesse meio é centrada na forma escrita (MARCUSCHI, 2005), o conceito de texto tem sido amplamente modificado.

Na visão de Charney (1994, p. 1), o texto é tradicionalmente conceituado como "uma coleção de ideias que um autor cuidadosamente seleciona, emoldura, e organiza em uma sequência ou padrão coerente visando influenciar o conhecimento, as atitudes ou ações do leitor ${ }^{1}$ ". O elemento-chave dessa concepção de texto é a estrutura. A visão de texto como uma sucessão ordenada de ideias é reforçada pela estrutura padrão do texto impresso: páginas que normalmente são lidas do topo para baixo e da esquerda para a direita.

\footnotetext{
${ }^{1}$ No original: "Most people conceive of text as a collection of ideas that a writer has carefully selected, framed, and organized into a coherent sequence or pattern in hopes of influencing a reader's knowledge, attitudes, or actions".
} 
Uma nova concepção de texto, entretanto, vem sendo adotada pela Linguística Textual, segundo a qual "todo texto constitui uma proposta de sentidos múltiplos e não de um único sentido, e [...] todo texto é plurilinear na sua construção" $(\mathrm{KOCH}$, 2003, p. 61).

Segundo Coscarelli (1999), além de mudanças na estrutura e na organização textual, as novas tecnologias trazem consigo novas linguagens e novos tipos de texto:

\begin{abstract}
O texto deixa de ser um todo contíguo [...] de estrutura unicamente linear, quase que unicamente verbal, e passa a ter uma estrutura hierárquica fragmentada, da qual fazem parte ícones, imagens estáticas e /ou animadas e sons. [...] O texto também sofre modificações na sua estrutura organizacional, que passa de uma sequência linear definida pelo seu produtor a uma sequência escolhida pelo leitor. (COSCARELLI, 1999, p. 84)
\end{abstract}

Os textos disponibilizados na Internet apresentam-se de forma heterogênea, variando muito com relação à forma e à linguagem em função dos diversos ambientes em que são encontrados. Alguns teóricos categorizaram o conteúdo da Internet em diferentes ambientes, dentre eles, os que incluem prioritariamente a linguagem na modalidade escrita, temos: o ambiente chat (bate-papo), o ambiente e-mail (correio eletrônico), os fóruns e grupos de discussão e o ambiente Web. Em cada um deles circulam diferentes gêneros emergentes da tecnologia digital, alguns já consolidados socialmente e outros ainda em construção, pois, como afirma Marcuschi (MARCUSCHI, 2005, p. 19), "a Internet transmuta de maneira bastante complexa gêneros existentes, desenvolve alguns realmente novos e mescla vários outros".

O chat é uma forma de comunicação síncrona que simula a interação face a face. Pode ocorrer entre duplas ou em grupos maiores, de forma aberta (pública) ou fechada (privada). Em função da velocidade necessária à digitação, é comum o uso de abreviações e a omissão de acentos. A linguagem se torna, então, menos rígida com relação às normas do Português padrão. Apresenta convenções próprias como o uso de diferentes símbolos (smileys ou emoticons) para indicar 
aspectos emocionais. Novas ferramentas têm permitido também o uso de chats de voz e vídeo aliados ao chat de texto. De modo geral, entre os gêneros mais conhecidos e estudados que circulam no ambiente chat temos: o chat em aberto, o chat reservado, o chat agendado, o chat privado, a entrevista com convidado, a aula chat e a videoconferência interativa (MARCUSCHI, 2005).

O e-mail "é uma forma de comunicação escrita normalmente assíncrona de remessa de mensagens entre usuários do computador" (MARCUSCHI, 2005, p. 39). Os textos que circulam nesse ambiente se assemelham aos textos de correspondência da modalidade manuscrita e/ou impressa (carta e bilhete, por exemplo), já que incluem destinatário, mensagem, despedida e o remetente, ao final. Por outro lado, incluem novos elementos como, por exemplo, o assunto, a inserção automática da data e hora em que a mensagem foi enviada, a possibilidade de inserção de destinatários em cópia (CC) ou em cópia oculta (CCO) e a possibilidade do envio de arquivos em anexo. Em função do propósito comunicativo, os e-mails podem apresentar uma linguagem mais ou menos formal. Entre os principais gêneros que circulam no ambiente e-mail, temos o email pessoal, o e-mail de trabalho e o e-mail educacional (aula virtual).

Os fóruns e grupos de discussão se constituem em um ambiente onde são discutidos temas específicos por pessoas que têm interesses em comum. É um ambiente que envolve vários gêneros e o principal deles é a lista de discussão. Nela, pessoas com interesses específicos se comunicam em geral de forma assíncrona, com o uso de e-mails, sob a mediação de um ou mais moderadores.

O ambiente web refere-se ao ambiente das páginas dos sites cujos textos estão conectados por meio de links. Incluem também o uso de material multimídia em forma de imagens, arquivos de áudio, vídeo e animações. Normalmente os textos publicados no ambiente web são definidos como hipertextos ou hipermídias, em função de aspectos de interatividade, intertextualidade e hipermodalidade. No ambiente web, circula uma grande variedade de gêneros digitais como portais educativos, enciclopédias, blogs, sites corporativos, sites jornalísticos, entre 
outros. Inicialmente, apenas os usuários com conhecimento em $\mathrm{HTML}^{2}$ publicavam conteúdo no ambiente web. Com o desenvolvimento de ferramentas da Web 2.0, onde o conteúdo foi separado da forma (formatação com o uso de linguagem de programação), cada vez mais pessoas publicam nesse ambiente.

Em função do trabalho realizado, a ser detalhado nas próximas seções, priorizaremos aqui o ambiente web e, mais especificamente, o gênero digital blog.

Segundo Marcuschi (2005), a expressão blog surgiu no final de 1997 para descrever sites pessoais que fossem atualizados frequentemente e contivessem links e comentários. O termo surgiu a partir da junção de duas palavras: Web, se referindo à rede mundial de computadores, e log, uma espécie de diário de bordo usado por navegadores. "Daí a expressão weblog que se popularizou na abreviação blog" (MARCUSCHI, 2005, p. 60), com a utilização do software Blogger, concebido como "uma alternativa popular para a publicação de textos online, uma vez que a ferramenta dispensava conhecimento especializado em computação" (KOMESU, 2005, p. 111 - grifos no original). Dentre os principais atributos da ferramenta que contribuíram para o seu sucesso, temos a "facilidade para a edição, atualização e manutenção de textos em rede" e "a convivência de múltiplas semioses, a exemplo de textos escritos, de imagens", de sons e de vídeos (KOMESU, 2005, p. 111). Atualmente, inúmeras ferramentas disponíveis gratuitamente na web permitem a criação de blogs (como o Blogspot e o Wordpress, por exemplo) e todas elas mantêm os mesmos atributos.

Komesu (2005) define blog como:

\begin{abstract}
Um espaço em que o escrevente pode expressar o que quiser na atividade da (sua) escrita, com a escolha de imagens e de sons que compõem o todo do texto veiculado pela Internet. [...] A aproximação dos blogs ao gênero dos diários pode ser justificada pela projeção de uma imagem estereotipada daquele que se ocupa de escritos pessoais. Quem escreve sobre si, para narrar acontecimentos íntimos, insere-se na prática diarista. (KOMESU, 2005, p. 113-114).
\end{abstract}

\footnotetext{
${ }^{2}$ HTML - HyperText Markup Language - é uma linguagem de marcação utilizada para produzir páginas na Web.
}

Texto Digital, Florianópolis, Santa Catarina, Brasil, v. 11, n. 1, p. 21-45, jan./jun. 2015. ISSNe: 1807-9288. 
A autora destaca ainda quatro eixos na produção textual dos blogs: tempo, espaço, interatividade e intertextualidade.

Com relação ao primeiro eixo (tempo), cumpre ressaltar que as ferramentas para a criação de blogs normalmente informam, automaticamente, no cabeçalho de cada postagem, a data e horário da produção textual. Evidencia-se, assim, "a vontade do indivíduo de 'ritmar o tempo' para a historização de si mesmo" (KOMESU, 2005, p. 114).

Se a questão do tempo é bem marcada nos blogs, o mesmo não ocorre com a questão do espaço, "já que não há um dispositivo automático que identifique e exponha o lugar de onde se escreve" (KOMESU, 2005, p. 114), sendo necessárias diferentes escolhas lexicais dentro das postagens para se determinar o "espaço" onde a produção textual foi realizada.

Com relação ao terceiro eixo, é importante destacar que a interatividade é uma das principais características atribuídas aos suportes eletrônicos da Internet. No caso dos blogs, ela se concretiza tanto na interface homem-máquina (em função da facilidade de edição e publicação de conteúdo), como na interação entre o usuário e outros usuários (em função da linguagem dialógica presente no texto, da facilidade de acesso e da possibilidade de postagens de comentários por diferentes usuários).

Os blogs são redigidos para que as histórias pessoais sejam compartilhadas abertamente. [...] A prática de escrita dos blogs, entretanto, coloca em evidência as mais diversas questões humanas para que elas sejam lidas e discutidas pelo Outro. Não importa que outras pessoas reconheçam a depressão ou a falta de perspectiva profissional; o importante é que as histórias circulem e ocupem o espaço da rede. (KOMESU, 2005, p. 117-118).

O último eixo - a intertextualidade - se refere às relações explícitas e/ou implícitas estabelecidas entre as diferentes partes que compõem o texto (incluindo as diferentes postagens - texto, imagem, som, vídeo) e entre o texto do 
blog e outros textos. Nesse caso, as relações entre diferentes textos são explicitadas e concretizadas pelo mecanismo dos links das páginas hipertextuais.

Embora a ferramenta utilizada pelos nossos alunos não tenha sido desenvolvida originalmente para a criação de blogs e, portanto, não disponha de mecanismos automáticos para a definição do "tempo" e nem para a inserção de links e publicação de comentários, ela teve o seu uso modificado visando a facilitar a aquisição de letramento digital de nossos alunos com relação às características do gênero digital blog e aos eixos aqui apresentados.

Tendo discutido algumas características textuais e linguísticas presentes no ambiente digital que serviram de suporte ao nosso trabalho, apresentamos na seção seguinte a abordagem pedagógica subjacente às atividades desenvolvidas.

\section{O trabalho com projetos}

O trabalho com projetos tem sido uma temática amplamente discutida dentro das escolas da Educação Básica por docentes e especialistas da área educacional. Temos o projeto político-pedagógico da escola, o projeto temático do ano, do bimestre, o projeto de um determinado professor, o projeto da horta, o projeto da biblioteca, o projeto da informática, o projeto de um grupo de alunos voluntários, etc. Mas como podemos definir o que seja projeto? Quais são as proximidades e distanciamentos entre o trabalho com projetos e as práticas de sala de aula ditas convencionais? Qual é a origem do trabalho com projetos?

De acordo com Prado (2005), a palavra projeto deriva do latim projectus, que significa "algo lançado para frente". "A ideia de projeto envolve, [portanto], a antecipação de algo desejável que ainda não foi realizado, traz a ideia de pensar uma realidade que ainda não aconteceu" (PRADO, 2005, p. 14). Realidade essa que só será concretizada mediante a ação concreta de um indivíduo ou de um grupo de pessoas. Para a autora, um dos pressupostos básicos do projeto é, portanto, a autoria - seja ela individual, em grupo ou coletiva. Por outro lado, as 
pessoas normalmente só se engajam em um projeto para descobrir ou produzir algo novo, procurando respostas a questões ou problemas reais. "A ideia de projeto faz parte da essência do ser humano consciente de sua condição de incompletude, em busca incessante de transformar-se para atingir algo desejável e encontrar respostas às suas questões" (ALMEIDA, 2005, p. 39).

Acredita-se que o trabalho com projetos tenha surgido ainda nas décadas de 1920 e 1930 durante o movimento da Escola Nova ${ }^{3}$, sob o título de Pedagogia de Projetos, e estaria pautado nas ideias de John Dewey (1859-1952), filósofo e pedagogo norte-americano que defendia a unidade entre teoria e prática e a democracia.

Fernando Hernández, por outro lado, acredita existirem diferenças básicas entre a Pedagogia de Projetos da década de 1920, e os Projetos de Trabalho surgidos na década de 1980. Segundo ele,

A Pedagogia de Projetos trabalhava [dentro de] um modelo fordista, que preparava as crianças apenas para o trabalho em uma fábrica, sem incorporar aspectos da realidade cotidiana dentro da escola. [Já] os projetos de trabalho tentam uma aproximação da escola com o aluno e se vinculam muito à pesquisa sobre algo emergente. (HERNÁNDEZ, 2012, versão on-line, s.p.).

Para Hernández e Ventura,

a organização dos Projetos de trabalho se baseia fundamentalmente numa concepção da globalização entendida como um processo [...] no qual as relações entre conteúdos e áreas de conhecimento têm lugar em função das necessidades que traz consigo o fato de resolver uma série de problemas que subjazem na aprendizagem. (HERNÁNDEZ e VENTURA, 1998, p. 63).

Segundo esses autores, a principal função do Projeto de Trabalho é propiciar novas estratégias "de organização dos conteúdos escolares com relação a: 1) o

\footnotetext{
${ }^{3}$ A Escola Nova foi um movimento de renovação do ensino que ganhou impulso no Brasil principalmente na década de 30 , após a divulgação do Manifesto dos Pioneiros da Educação Nova (1932). Nesse documento, defendia-se a universalização da escola pública, laica e gratuita.
} 
tratamento da informação, e 2) a relação entre os diferentes conteúdos em torno de problemas ou hipóteses que facilitem aos alunos a construção de seus conhecimentos" (HERNÁNDEZ e VENTURA, 1998, p. 61). Somente assim, os alunos poderiam transformar a informação procedente dos diferentes saberes disciplinares em conhecimento próprio e significativo.

Embora apresente algumas variantes e diferentes designações (Pedagogia de Projetos ou Projeto de Trabalho, por exemplo), o trabalho pedagógico com projetos está pautado em duas concepções básicas: uma visão interdisciplinar do conhecimento e a necessidade de aproximarmos a sala de aula da vida dos alunos. Segundo Prado (PRADO, 2005, p. 1) "o trabalho com projetos inverte a lógica do currículo definido em grades de conteúdos temáticos estanques, induzindo o professor a colocar em jogo as problemáticas que permeiam o cotidiano".

Leite, Oliveira e Maldonato (1998) salientam que o trabalho com projetos não deve ser concebido apenas como uma nova técnica de ensino, mas deve se constituir em uma nova postura pedagógica.

\footnotetext{
É nessa perspectiva que, nos anos 90 , o trabalho com projetos, voltado para uma visão mais global do processo educativo, ganhou força no Brasil e no mundo. Não se trata de uma técnica atraente para transmitir aos alunos o conteúdo das matérias. Significa de fato uma mudança de postura, uma forma de repensar a prática pedagógica e as teorias que Ihe dão sustentação. Significa repensar a escola, seus tempos, seu espaço, sua forma de lidar com os conteúdos das áreas e com o mundo da informação. (LEITE, OLIVEIRA e MALDONATO, 1998, p. 58).
}

As autoras destacam ainda que, para que possamos assumir o trabalho com projetos como uma nova postura pedagógica, alguns aspectos são fundamentais como: (a) a problematização, (b) a autoria, (c) a autenticidade e (d) a incorporação de diferentes pontos de vista. Com relação ao primeiro aspecto, é importante destacar que a problematização é o fio condutor de todo o projeto. "Problematizar corresponde a construir coletivamente uma questão que irá acompanhar o grupo em todo o seu percurso e servirá de referência para 
debates, discussões e reflexões" (LEITE, OLIVEIRA e MALDONATO, 1998, p. 60). Com relação aos segundo aspecto, convém destacar que o envolvimento, a responsabilidade e a autoria dos alunos são fundamentais para o sucesso do projeto. A autenticidade é outro aspecto importante. Cada projeto se constitui de forma única e singular, pois é construído coletivamente por um grupo específico de pessoas sócio-historicamente situado. O último aspecto destacado pelas autoras se refere ao fato de todo projeto incorporar as diferentes vozes dos sujeitos nele envolvidos. Durante a realização de um projeto, busca-se "estabelecer conexões entre vários pontos de vista, contemplando [assim] uma pluralidade de dimensões" (LEITE, OLIVEIRA e MALDONATO, 1998, p. 60).

Nogueira (2001) argumenta que, para que o trabalho com projetos ocorra de forma efetiva, é necessário que se leve em conta algumas questões educativas essenciais: o conceito de conteúdo, os problemas de aprendizagem, a formação integral do aluno tendo em vista seu espectro de competências, a necessidade de rupturas com conceitos e posturas arraigadas, a problemática da interdisciplinaridade, a postura do professor enquanto mediador no trabalho com projetos e as novas tecnologias como ferramentas auxiliares.

Com relação aos conteúdos, é necessário que eles sejam tratados não apenas de forma conceitual, mas também de forma procedimental e atitudinal. Não basta trabalharmos com nossos alunos apenas os conteúdos conceituais, é necessário que eles aprendam também procedimentos como: diferentes abordagens de leitura; planejamento, execução, refinamento e avaliação de suas atividades; busca, seleção e armazenamento de informações obtidas da Web; trabalho em equipe; etc. Nogueira (2001, p. 23) defende, portanto, que "os procedimentos também devem ser tratados como objeto de ensino, e como tal necessitam da intervenção do professor mediando esta forma de aprendizagem". Além dos conteúdos procedimentais, é necessário que sejam trabalhados também as normas e valores - os conteúdos atitudinais -, pois de nada adiantará a escola se ela não for capaz de formar um cidadão consciente de sua função e papel em uma sociedade mais justa e democrática. 
Quanto aos distúrbios e problemas de aprendizagem, Nogueira (2001) destaca que muitas vezes eles são tratados de forma indiscriminada. Na realidade, a nãoaprendizagem normalmente estaria relacionada à não-aceitação das normas de disciplinas escolares, à má integração do aluno ao grupo, à má formação do professor e, principalmente, às práticas pedagógicas dissociadas da realidade do aluno.

\begin{abstract}
Sem querer encarar de forma simplista a situação da não-aprendizagem, sem esquecer dos distúrbios de aprendizagem por problemas emocionais, os problemas estruturais da família, da má alimentação, da motivação intrínseca e de dezenas de outros fatores que permeiam a aprendizagem, acreditamos que este "delta" entre a realidade externa e interna da escola é fator sim de desinteresse em aprender. (NOGUEIRA, 2001, p. 31).
\end{abstract}

No tocante à necessidade de estímulos nas diferentes áreas do espectro de competências, o autor destaca que muitas práticas educativas focam apenas as áreas lógico-matemática e linguística, quando deveriam propiciar ao aluno também o desenvolvimento de outras áreas como a espacial, a corporalcinestésica, a musical, a interpessoal, a intrapessoal, a naturalista, a existencial, a pictórica e a emocional.

Não será possível, entretanto, trabalhamos de forma diferenciada com os conteúdos, com práticas pedagógicas vinculadas à vida do aluno e voltadas ao desenvolvimento das diferentes áreas do espectro de inteligências, se não formos capazes de "romper com velhos paradigmas, com modelos mentais arraigados e com uma postura totalmente formal e tradicional nas ações pedagógicas" (NOGUEIRA, 2001, p. 67). Dentre os principais paradigmas a serem rompidos merecem destaque: a lógica do currículo definido em grades de conteúdos temáticos estanques, organizados em disciplinas e o papel do professor como transmissor do conhecimento. $\mathrm{O}$ trabalho com projetos, portanto, prioritariamente dentro de uma abordagem interdisciplinar, com o professor desempenhando o papel de mediador, poderá representar, de alguma forma, uma ruptura com 
experiências pedagógicas de não-aprendizagem muito comuns nas salas de aula de escolas brasileiras.

Outro aspecto destacado por Nogueira (2001) se refere à importância do uso das novas tecnologias no desenvolvimento de projetos. Um fator de grande destaque para o engajamento dos alunos em um projeto é a motivação. As crianças e adolescentes costumam ficar horas na frente do computador. "A aquisição $e$ descobertas no computador são tão rápidas e desafiadoras, que entretém facilmente as crianças, fazendo com que elas aceitem novos desafios a cada momento, e por consequência continuem a descobrir e criar" (NOGUEIRA, 2001, p. 178). A informática, portanto, representa por si só um grande elemento de motivação para os alunos e, se for agregada ao trabalho com projetos, poderá potencializar nos alunos a motivação em aprender, em construir conhecimento. "É exatamente sobre esta possibilidade de propiciar atividades que venham restabelecer o equilíbrio da criança e promover atividades que façam persistir nela, é que cremos ser a informática uma grande ferramenta para estes fins" (NOGUEIRA, 2001, p. 175).

Nogueira (2001) acredita que os trabalhos de autoria com o uso do computador incluem as mesmas etapas apresentadas por ele para o trabalho com projetos.

Seguindo as mesmas etapas de elaboração de um projeto tradicional, para os trabalhos de autoria o aluno também:

- Planeja ${ }^{4}$ (do que vai ser autor, como vai fazer, etc.)

- Executa (cria tela, constrói textos, captura imagens e sons, determina ações, movimentos, etc.)

- Depura (principalmente os textos pesquisados, pois na criação de um documento Web ou no material multimídia, os textos devem ser sintéticos - ainda depura a qualidade gráfica e estética de seu material criado, preocupando-se com o designer e layout);

- Apresenta e expõe (no caso de um documento Web, expõe em um site para toda a comunidade de internautas, e no caso de um material multimídia, pode apresentar para diferentes pessoas por meio de um CD-rom ou mesmo diretamente do computador);

- Avalia (neste caso com o auxílio dos professores e demais alunos envolvidos, o processo de avaliação transcorre da mesma forma

\footnotetext{
${ }^{4}$ Ao apresentar as etapas de um projeto, Nogueira (2001:96) cita ainda uma etapa anterior ao planejamento, identificada como "Sonhos, utopias, desejos e necessidades".
} 
como já mencionado anteriormente ${ }^{5}$ ). (NOGUEIRA, 2001, p. 181 grifos no original).

Prado (2005) argumenta que o trabalho com projetos representa um grande desafio para o professor. Se por um lado ele "pode viabilizar ao aluno um modo de aprender baseado na integração entre conteúdos das várias áreas do conhecimento, bem como entre diversas mídias" (PRADO, 2005, p. 14), por outro lado, ele não é de fácil implementação em função da forma com que as escolas são organizadas. Na maioria delas, a grade curricular é sequencial, os conteúdos são fragmentados em disciplinas, o espaço é limitado à sala de aula, o horário de aula restrito a 50 minutos e o tempo de aprendizagem dividido em bimestres ou trimestres. Em função disso, muitos paradigmas precisam ser rompidos currículo, conteúdo, espaço e tempo - para que um projeto se concretize.

\begin{abstract}
A pedagogia de projetos deve permitir que o aluno aprenda-fazendo e reconheça a própria autoria naquilo que produz por meio de questões de investigação que Ihe impulsionam a contextualizar conceitos já conhecidos e descobrir outros que emergem durante o desenvolvimento do projeto. [...] $\mathrm{O}$ trabalho por projeto potencializa a integração de diferentes áreas de conhecimento, assim como a integração de várias mídias e recursos, os quais permitem ao aluno expressar seu pensamento por meio de diferentes linguagens $e$ formas de representação. (PRADO, 2005, p. 15)
\end{abstract}

Conforme discutido nesta seção, o trabalho com projetos pode ser analisado com base em diferentes perspectivas e abordagens. Entre o projeto possível de ser realizado e o projeto ideal há um longo e difícil caminho a trilhar. O projeto a ser descrito na próxima seção não foi realizado de forma multidisciplinar e, infelizmente, não contou com o envolvimento e participação de toda a comunidade escolar. Alguns teóricos talvez nem o considerem como projeto de trabalho, na acepção restrita do termo. Ele surgiu dos "sonhos, utopias, desejos e necessidades" $^{6 \prime}$ das professoras-pesquisadoras que redigem este relato em

\footnotetext{
${ }^{5}$ Nogueira (2001:105) destaca que a etapa de avaliação não deve ocorrer de forma estanque ao final do projeto. $O$ professor poderá mediar sessões de avaliação durante a realização das atividades. Dessa forma, as críticas funcionarão como feedback oportunizando a melhoria do projeto.

${ }^{6}$ Nogueira (2001) define dessa forma a etapa inicial de todo projeto de trabalho.
} 
função de um caso de bullying ocorrido em nossa comunidade escolar, como será relatado a seguir.

\section{Descrição do projeto realizado}

O projeto Todos contra o bullying ${ }^{7}$ foi realizado com seis turmas de sexto ano no segundo semestre de 2013. Ainda durante a realização de um projeto anterior, no mês de maio, a comunidade escolar foi surpreendida pela criação de uma comunidade de bullying no $A s k^{8}$ por alunas do oitavo ano. Esse fato motivou o envolvimento de alguns docentes na realização de atividades que visassem a inibir casos de preconceito entre os alunos. Sendo assim, as equipes de Informática Educativa e de Língua Portuguesa planejaram e implementaram o projeto intitulado Todos contra o bullying, em referência ao livro Todos contra Dante que serviu de inspiração para o projeto.

No site do laboratório de Informática Educativa, o projeto foi apresentado da seguinte forma:

\footnotetext{
Tendo como inspiração a leitura do livro Todos contra Dante, em que o autor Luís Dill se baseia em fatos reais para criar literatura, cada aluno selecionou um caso real de bullying noticiado na mídia, criou murais online de recortes das notícias sobre o caso e elaborou um texto em $1^{\text {a }}$ pessoa se colocando no lugar da vítima que desabafa todo o seu sofrimento. Esse texto foi publicado em um microblog.
}

O livro Todos contra Dante, que serviu de base para o projeto, apresenta uma narrativa diferenciada de natureza hipertextual e intertextual. Com relação à natureza intertextual, percebe-se claramente que o texto é permeado por quatro textos interconectados: os diálogos dos agressores, uma comunidade de bullying criada contra o personagem principal (Dante), um blog onde a vítima desabafa todo o seu sofrimento e trechos da obra A Divina Comédia de Dante Alighieri. O

\footnotetext{
7 Detalhes sobre 0 projeto disponíveis em: https://sites.google.com/site/ re2todoscontraobullying/home. Nesse endereço, pode-se ter acesso às etapas referentes ao trabalho de leitura literária propriamente dita.

${ }^{8} \mathrm{O}$ Ask (http://ask.fm/) é uma rede social de perguntas e respostas. Nessa rede, é possível responder e questionar, anonimamente ou não, amigos e também desconhecidos.
} 
caráter hipertextual da narrativa é marcado pela sequência da leitura que é determinada pela palavra [link] exibida em vários pontos da obra. Visando a preparar os alunos para a leitura do livro, foi elaborada uma apresentação em Power Point com trechos do livro e hiperlinks de modo a simular a navegação hipertextual proposta pela narrativa.

Fig. 1 e 2 - Telas da apresentação do livro Todos contra Dante ${ }^{9}$.

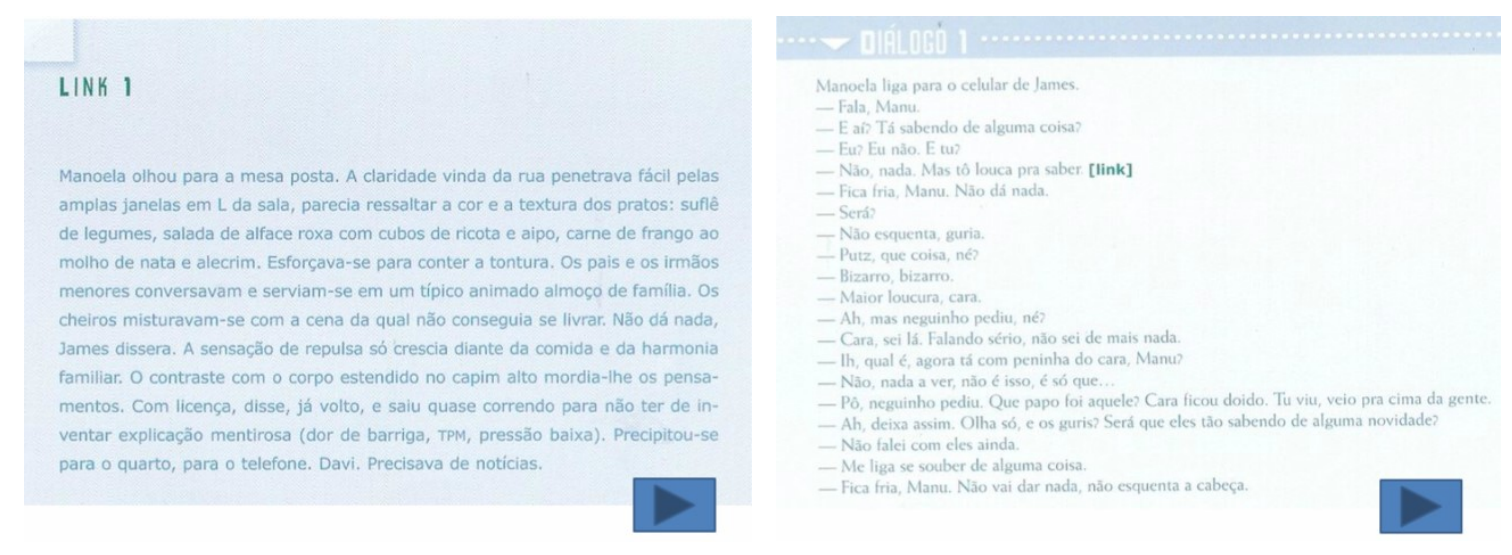

Como pode ser observado, a escolha da obra literária adotada se justifica não apenas pela temática abordada (no caso, o bullying), mas também em função de aspectos hipertextuais e intertextuais presentes na narrativa. Ou seja, embora o texto tenha sido veiculado somente no suporte impresso, ele apresenta características do suporte digital, que foram exploradas pedagogicamente de forma intencional visando à produção textual dos alunos.

A principal ferramenta utilizada durante a realização do projeto possibilita a criação de murais virtuais e, atualmente, é conhecida no ambiente Web como Padlet $^{10}$. Ao todo cada aluno construiu três murais no Padlet. No primeiro, os alunos deveriam apresentar três definições para bullying com suas respectivas fontes e inserir imagens ilustrativas. Ao inserir as fontes, deveriam ativar os links para os referidos sites. No segundo mural, cada aluno inseriu recortes de notícias

\footnotetext{
${ }^{9} \mathrm{O}$ livro é lido iniciando-se sempre pela página da direita até o trecho onde aparece a expressão [link]. O fluxo da leitura passa, então, para a página da esquerda que corresponde ao referido link. Depois retorna-se à página da direita até que a leitura da mesma possa ser concluída.

${ }^{10} \mathrm{Na}$ época do projeto, a ferramenta estava disponível apenas em Inglês (http://www.padlet.com). Atualmente uma versão em Português está disponível em: https://pt-br.padlet.com/.
} 
de diferentes fontes sobre um caso real de bullying selecionado por ele $^{11}$. No último mural, organizado em forma de blog, cada aluno publicou um texto em primeira pessoa se colocando no lugar da vítima do caso selecionado que relata todo o seu sofrimento (a exemplo do que o personagem Dante havia feito no livro).

Durante a produção textual, os alunos foram orientados sobre algumas características do gênero digital blog como o uso da $1^{\text {a }}$ pessoa, a linguagem dialógica (estabelecendo um diálogo com um interlocutor "confidente"), a marcação do "tempo" no cabeçalho de cada postagem, a inserção de imagens, letras de música e outros tipos de mídias que dialogassem com o texto, além de links para outros textos. Foram orientados também a estabelecer relações de coerência entre o texto produzido e as notícias sobre o caso selecionado. Dessa forma, foram ressaltados também aspectos de intertextualidade e de multissemiose, já que era necessária, por parte do aluno, a manipulação de diferentes meios semióticos: o visual, o verbal e, eventualmente, o sonoro. Todos os trabalhos foram organizados em um ambiente do Google Sites, de forma que circulassem socialmente e cumprissem objetivos comunicativos reais. Portanto, para além do manejar das novas ferramentas de produção textual (promoção da alfabetização tecnológica), o projeto permitiu aos alunos se inserirem em práticas sociais de leitura e escrita, ou seja, contribui para o multiletramento dos mesmos.

Com o objetivo de facilitar a visualização dos três murais em sequência, cada aluno teve seus murais incorporados em uma única página no Google Sites e as diferentes páginas foram organizadas em função da turma do aluno. Além dos murais, foram publicados também os roteiros de trabalho e demais materiais didáticos produzidos.

\footnotetext{
${ }^{11}$ Visando a evitar que os alunos selecionassem sempre os mesmos casos em função dos resultados obtidos pelos motores de busca, foi feito um levantamento prévio de mais de quarenta casos organizados em quatro categorias: bullying por racismo, bullying por orientação sexual, bullying por característica física e bullying por escolha religiosa. A lista completa com todos os casos pode ser obtida no endereço: https://sites.google.com/site/re2todoscontraobullying/sobre-oprojeto.
} 
Fig. 3 - Exemplo de $1^{\circ}$ mural - Projeto Todos contra o bullying.

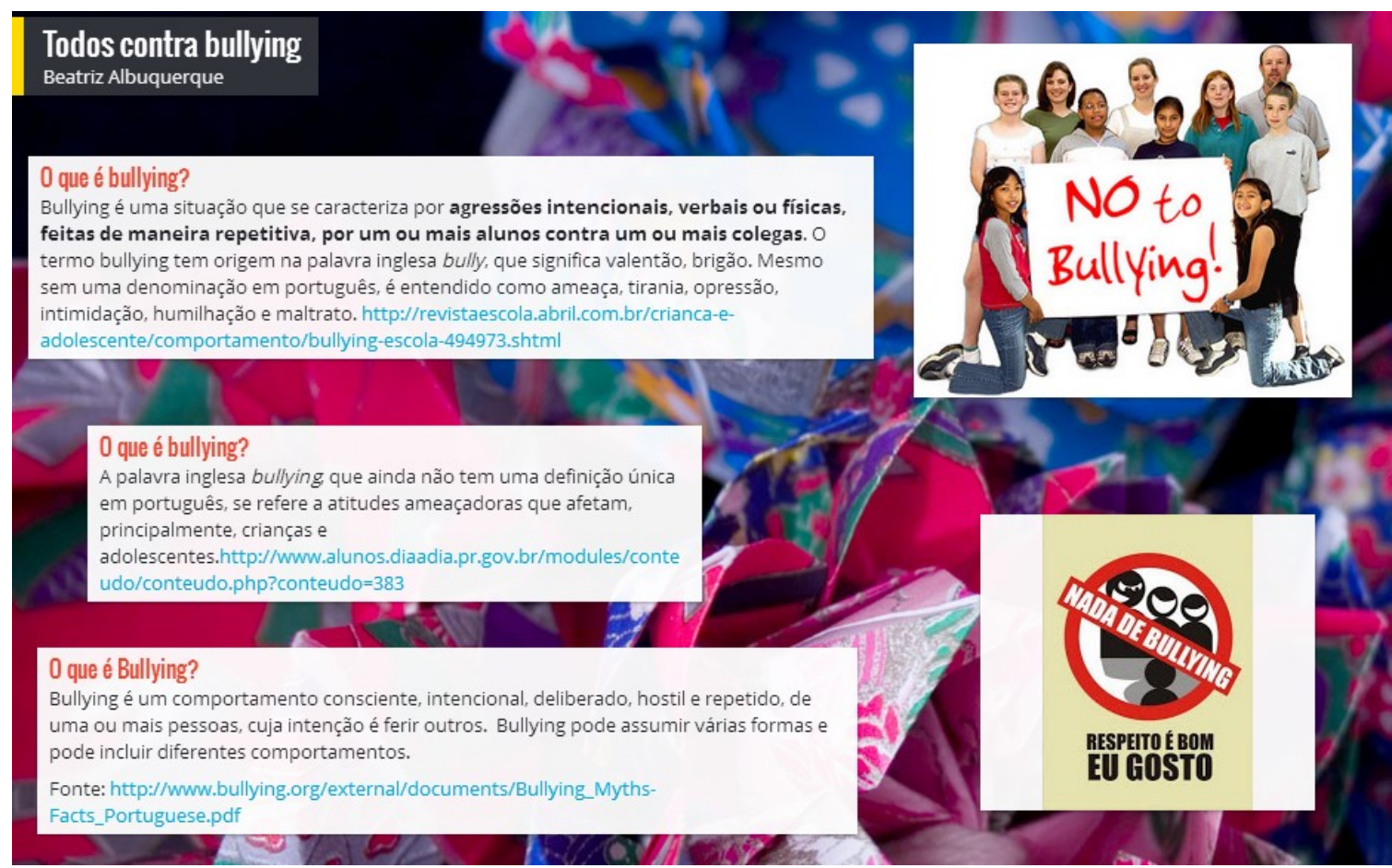

Fig. 4 - Exemplo de $2^{\circ}$ mural - visão parcial - Projeto Todos contra o bullying.

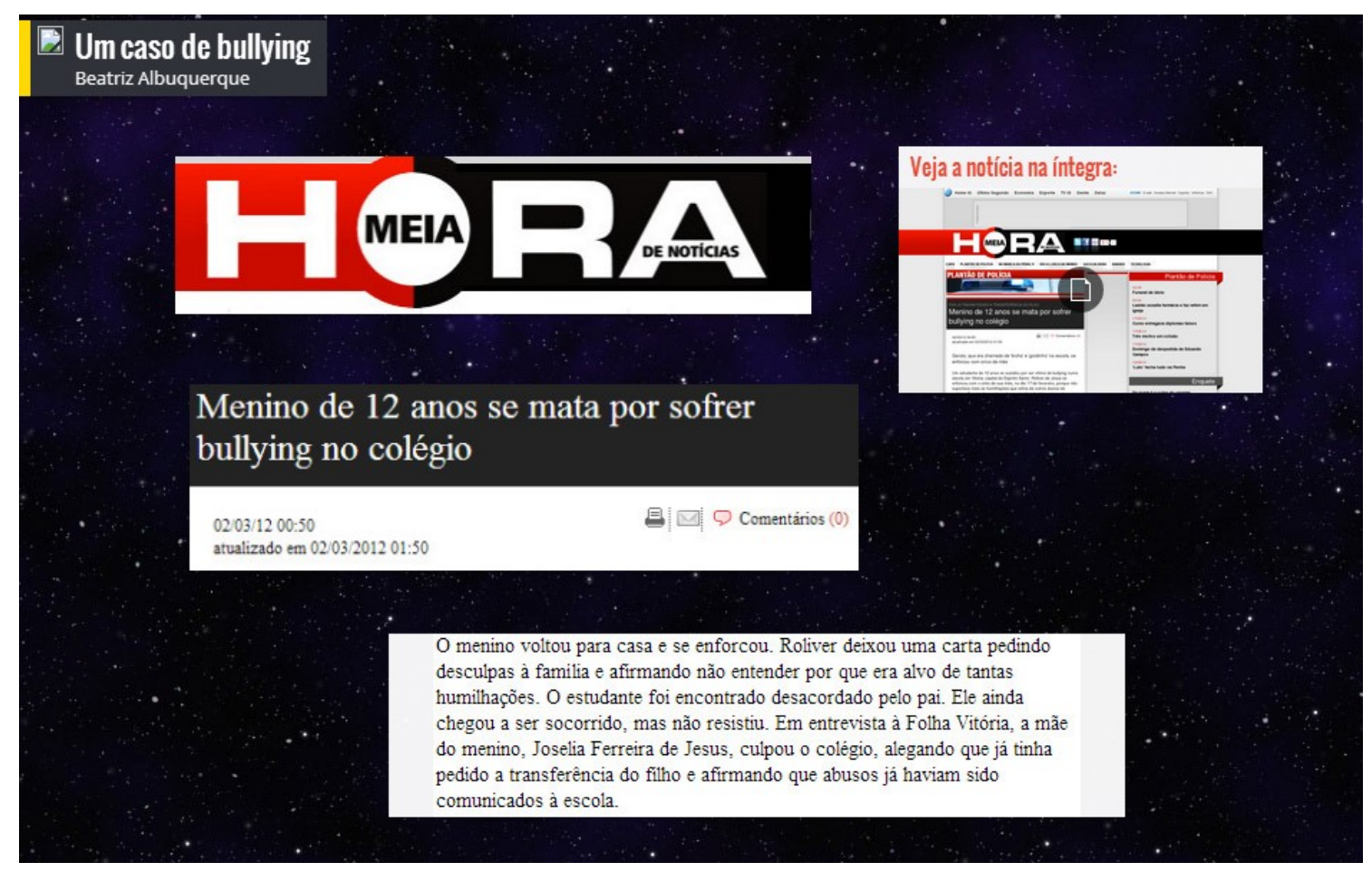

Texto Digital, Florianópolis, Santa Catarina, Brasil, v. 11, n. 1, p. 21-45, jan./jun. 2015. ISSNe: 1807-9288. 
Fig. 5 - Exemplo de $3^{\circ}$ mural - visão parcial - Projeto Todos contra o bullying ${ }^{12}$.

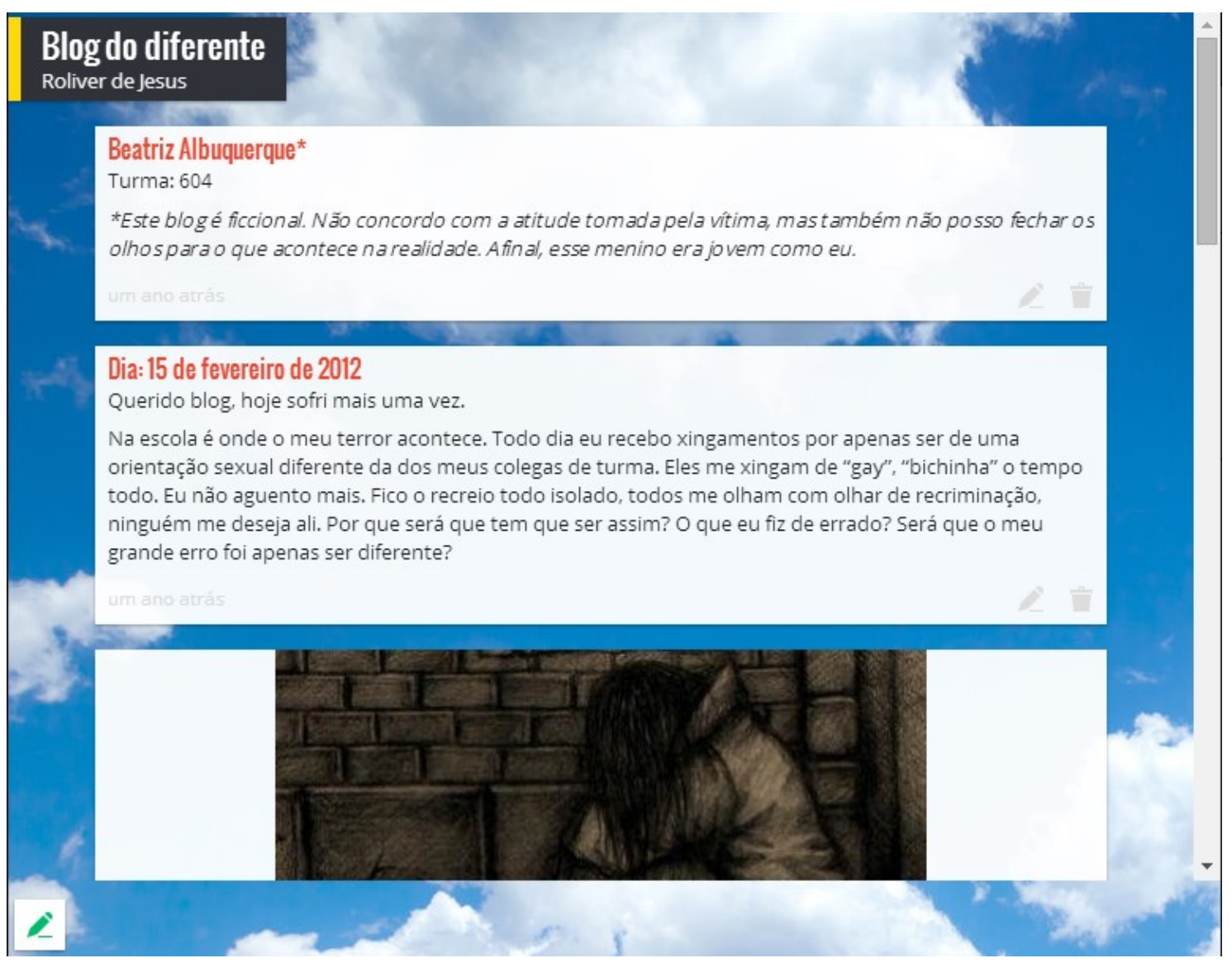

Cumpre ressaltar que os textos foram digitados diretamente no Word e, no início da aula com a primeira turma, os alunos tiveram muita dificuldade em iniciar o texto. Decidimos, então, durante a aula, interferir propondo que todos iniciassem seu texto com a mesma frase: "Querido blog, hoje sofri mais uma vez". O início da frase ("Querido blog") foi escolhido por associação à expressão: "Querido diário". Já a segunda parte foi escolhida de modo a sintetizar o conceito de bullying: ação preconceituosa repetitiva que causa sofrimento à vítima. A estratégia surtiu um ótimo efeito e foi adotada também com as demais turmas. Posteriormente, os textos foram corrigidos utilizando-se a ferramenta de controle de alterações do Word, de forma que os alunos tiveram que voltar às suas produções escritas para revisá-las e fazer as alterações necessárias. Talvez por conta da novidade, ou porque soubessem que seus textos seriam publicados na Web e, portanto, seriam lidos não só pelas professoras, o envolvimento dos alunos nesta etapa foi muito

\footnotetext{
${ }^{12}$ Mural original disponível em: http://pt-br.padlet.com/beatrizalbuquer/blog_604beatriz07. 
satisfatório. Eles estavam se sentindo, enfim, autores de seus textos, produtores de sentido.

É importante destacar também que uma das características do gênero digital blog - o uso da primeira pessoa - foi utilizada como estratégia de produção textual literária e de conscientização dos alunos sobre as causas e consequências do preconceito, já que o "eu" apresentado no blog era um "eu" ficcional. Ou seja, a narrativa em primeira pessoa favorecia a aproximação e identificação de cada aluno com o sofrimento e angústia da vítima do caso de bullying selecionado por ele. Acreditávamos que, assim, talvez, fazendo o exercício de se colocar no lugar do outro, os alunos poderiam pensar duas vezes antes de fazer ao próximo aquilo que não gostariam que fizessem com eles. Dessa forma, o projeto também cumpriu o seu papel no letramento literário de nossos alunos por duas vias: em primeiro lugar, porque puderam experimentar, por meio da escrita, o mecanismo de engendramento do texto ficcional, que se baseia em um recorte transfigurado real; em segundo lugar, porque, colocando-se no lugar do outro, tiveram a oportunidade de vivenciar um alargamento de seus horizontes de expectativas e proceder a uma revisão crítica do mundo, efeitos desejados da leitura literária. Entretanto, em função do recorte feito neste relato, esse aspecto do trabalho não será detalhado.

Depois dos textos produzidos, corrigidos e publicados, identificamos alguns com o mesmo final trágico da história original em que a vítima se suicidava ou era morta pelo agressor. Receosas de que esse fato pudesse desencadear em nossos alunos um sentimento de impotência frente ao bullying, decidimos que, no caso dessas produções, deveria ser incluído o seguinte trecho: "*Este blog é ficcional. Não concordo com a atitude tomada pela vítima, mas também não posso fechar os olhos para o que acontece na realidade. Afinal, esse/a menino/a era jovem como eu." A inserção desse trecho foi discutida com os alunos, que compreenderam a necessidade do mesmo, principalmente porque os trabalhos seriam disponibilizados de forma pública na Web. Nossa cautela se justificava pelo fato de nossos alunos terem passado por todo um processo de reflexão 
sobre o bullying, diferentemente dos demais potenciais leitores, que poderiam interpretar os finais trágicos de forma equivocada.

O projeto Todos contra o bullying foi apresentado durante a Semana Cultural (de 21 a 25 de outubro de 2013) pelos próprios alunos do $6^{\circ}$ ano. O público-alvo das apresentações era formado por turmas de $8^{\circ}$ ano, mesmo ano de escolaridade em que três alunas haviam criado a referida comunidade no Ask para difamar algumas alunas de $1^{\circ}$ ano do Ensino Médio. Durante a Semana Cultural, os alunos do $6^{\circ}$ ano também participaram de um debate com as autoras da coleção Era uma vez o bullying da editora Garamond. O envolvimento dos alunos no projeto se tornou evidente principalmente a partir da análise das postagens feitas no Facebook nos grupos da Ciranda de leitura ${ }^{13}$. Essas postagens se referiam às discussões ocorridas em aula, ao livro Todos contra Dante e aos livros da coleção Era uma vez o bullying.

Tomando como base as etapas propostas por Nogueira (2001), o projeto pode ser analisado da seguinte forma:

Quadro 1 - Etapas do projeto Todos contra o bullying.

\begin{tabular}{|c|c|}
\hline $\begin{array}{l}\text { Sonhos, } \\
\text { utopias, } \\
\text { desejos e } \\
\text { necessidades }\end{array}$ & $\begin{array}{l}\text { O projeto foi idealizado pelas professoras-pesquisadoras que assinam } \\
\text { este relato em decorrência de um caso de bullying ocorrido na } \\
\text { comunidade escolar. }\end{array}$ \\
\hline Plan & $\begin{array}{l}\text { Embora os níveis de engajamento fossem distintos, todos participaram do } \\
\text { planejamento das ações, inclusive os alunos. }\end{array}$ \\
\hline $\begin{array}{l}\text { Execução e } \\
\text { realização }\end{array}$ & $\begin{array}{l}\text { Cada aluno pesquisou sobre o conceito de bullying, selecionou um caso } \\
\text { real noticiado na mídia, capturou recortes de reportagens on-line em } \\
\text { forma de imagens, elaborou um texto próprio em primeira pessoa se }\end{array}$ \\
\hline
\end{tabular}

\footnotetext{
${ }^{13}$ A dinâmica da Ciranda funciona mais ou menos assim: cada aluno que deseja participar da Ciranda deve postar no Facebook, na página do grupo da sua turma, a resenha de um livro lido espontaneamente e do qual tenha gostado. Depois, esse livro deve ser disponibilizado para empréstimo na turma. Todos os interessados na leitura do livro colocam seu nome nos comentários abaixo da postagem da resenha, formando assim uma lista de espera, e, à medida que os livros são lidos, a Ciranda é movimentada. Os alunos também são estimulados a comentar criticamente os livros que pegam emprestados, de forma a instaurar no espaço digital uma comunidade de leitores que partilham referências e modos de leitura, ou seja, se apropriam da leitura literária enquanto prática social e não apenas escolar.
} 
colocando no lugar da vítima e produziu diferentes murais on-line como forma de registrar todo o processo de trabalho.

Depuração $\quad$ As correções feitas de forma digital diretamente no documento de texto
(com o controle de alterações do Word) facilitaram a reescrita textual. Os
comentários feitos durante as aulas a respeito das primeiras versões dos
trabalhos (produções textuais e murais) também favoreceram a etapa de
depuração.

Apresentação Os trabalhos foram publicados em um ambiente do Google Sites. Cada e exposição aluno tinha sua própria página onde eram publicados os três murais em sequência. Todos os trabalhos de todas as turmas foram organizados em um ambiente único, o que favoreceu a concepção de trabalho coletivo. Dessa forma, todos tinham acesso fácil ao trabalho de todos. A apresentação oral dos trabalhos feita por alguns alunos voluntários durante a Semana Cultural para turmas de $8^{\circ}$ ano também foi de grande importância para o projeto. Esses alunos depois relataram para suas turmas com muito entusiasmo a experiência.

$\begin{array}{ll}\text { Avaliação e } & \text { As avaliações e críticas ocorreram durante todo o projeto e incluíram } \\ \text { críticas } & \text { principalmente as sugestões de modificação nos textos com o uso do } \\ & \text { controle de alterações do Word e várias interações em aula com } \\ & \text { orientações sobre a reorganização dos murais. Como os trabalhos foram } \\ & \text { submetidos ao público externo, os alunos também receberam críticas dos } \\ & \text { colegas de outras turmas do } 6^{\circ} \text { e do } 8^{\circ} \text { ano e também das autoras da } \\ & \text { coleção sobre o bullying durante o debate realizado com elas na Semana } \\ & \text { Cultural. O projeto também foi divulgado por e-mail ao escritor Luís Dill, } \\ & \text { autor do livro Todos contra Dante, o qual serviu de inspiração para a } \\ & \text { realização do projeto. Este, gentilmente, respondeu à mensagem tecendo } \\ & \text { muitos elogios ao trabalho, os quais foram repassados aos alunos. }\end{array}$

\section{Considerações finais}

O projeto aqui apresentado e outros já realizados em nossa instituição, a partir da parceria entre a Informática Educativa e a disciplina de Língua Portuguesa, nos permitem vislumbrar possibilidades de uso pedagógico das NTICs para a promoção de diferentes letramentos de alunos da Educação Básica: o letramento impresso, o digital e o literário. 
Neste relato, em função do recorte feito, destacamos a articulação entre o letramento impresso e o letramento digital a partir de um detalhamento das atividades realizadas durante o projeto Todos contra o bullying, em que alunos do $6^{\circ}$ ano produziram murais on-line (sendo um deles em formato de blog - um gênero textual digital) a partir da leitura do livro Todos contra Dante (produzido para o suporte impresso, mas com elementos característicos do suporte digital como a hipertextualidade e a intertextualidade). Dessa forma, acreditamos que o trabalho realizado cumpriu o seu papel na formação de leitores para atuar em uma sociedade cada vez mais tecnológica, pois, como afirma Martín-Barbero:

\begin{abstract}
[...] estamos diante de uma mudança nos protocolos e processos de leitura, que não significa, nem pode significar, a simples substituição de um modo de ler por outro, senão a articulação complexa de um e outro, da leitura de textos e da de hipertextos, da dupla inserção de uns em outros, com tudo o que isso implica de continuidades e rupturas, de reconfiguração da leitura como conjunto de modos muito diversos de navegar pelos textos. Pois é por essa pluralidade de escritas que passa, hoje, a construção de cidadãos, que saibam ler tanto jornais como noticiários de televisão, videogames, videoclipes e hipertextos. (MARTÍN-BARBERO, 2001, p. 3)
\end{abstract}

Conforme destacado, o projeto surgiu em decorrência de um caso real de bullying ocorrido em nossa instituição escolar. Os alunos foram orientados a pesquisar sobre outros casos reais de bullying noticiados na mídia digital. Dessa forma, procurou-se aproximar a sala de aula do que ocorre fora dela, no cotidiano das pessoas. Depois, cada aluno foi convidado a se colocar no lugar da vítima e a produzir um texto em primeira pessoa, relatando o possível sofrimento sofrido por ela. À medida que os textos foram publicados, os alunos puderam conhecer as histórias de inúmeras outras vítimas a partir da produção literária de seus pares. Em função da linguagem dialógica presente nos textos, enquanto leitores, eles também eram "interlocutores confidentes" e, como tal, não poderiam ficar imunes aos "pedidos de socorro" presentes nos textos (de forma implícita e/ou explícita). Muitas vezes presenciamos por parte de nossos alunos reações de indignação com relação ao preconceito como se eles pudessem, realmente, "mudar o mundo". A participação dos alunos no projeto possibilitou neles um 
amadurecimento pessoal que não imaginávamos que pudesse ser atingido por alunos do $6^{\circ}$ ano (embora sempre tivéssemos sonhado com isso).

A análise dos resultados obtidos evidencia, portanto, que, além de propiciar a aquisição de diferentes letramentos por parte de nossos alunos, o projeto propiciou também a reflexão deles sobre diferentes casos de preconceito - por orientação sexual, por motivos religiosos, em função de características físicas, raciais ou étnicas - ocorridos na sociedade. Dessa forma, acreditamos ter conseguido abarcar as duas dimensões desejáveis do trabalho com multiletramentos em sala de aula, segundo Roxane Rojo (2008): a da multiplicidade de práticas de leitura e escrita presentes na contemporaneidade sendo elas mesmas multissemióticas e exigindo, portanto, competências e habilidades diversas de produção e recepção textual - e a da diversidade cultural trazida pelos alunos. Segundo a autora:

\begin{abstract}
Trabalhar com multiletramentos pode ou não envolver (normalmente envolverá) o uso de novas tecnologias de comunicação e de informação ("novos letramentos"), mas caracteriza-se como um trabalho que parte das culturas de referência do alunado (popular, local, de massa) e de gêneros, mídias e linguagens por eles conhecidos, para buscar um enfoque crítico, pluralista, ético e democrático - que envolva agência de textos/discursos que ampliem o repertório cultural, na direção de outros letramentos, valorizados [...] ou desvalorizados [...]. (ROJO, 2012, p. 8)
\end{abstract}

O uso das NTICs, no projeto em questão, serviu justamente para, a partir da cultura de referência dos alunos (a cibercultura, com sua linguagem própria e seus modos inovadores, e nem sempre éticos, de interação), propiciar uma visão crítica do real e dos usos da tecnologia, o que demonstrou ser um passo importante na construção de uma comunidade (quiçá de uma sociedade) menos preconceituosa e mais consciente acerca das consequências de seus atos.

\title{
PROJECT EVERYBODY AGAINST BULLYING: READING AND WRITING HYPERTEXTUAL PRACTICES BY MIDDLE SCHOOL STUDENTS
}

ABSTRACT: The wide expansion of electronic communication networks - the Internet - is causing profound impacts on society, mainly on the way people process information and construct knowledge. As language available in online environment is centered on written form, the concept of 
text has been extensively modified - hypertext, hypermedia, multimedia. In view of the above, school has to develop pedagogical practices that meet the demands of today's society in order to provide students with the acquisition of different types and layers of literacy. This paper reports an experiment conducted with six groups of $6^{\text {th }}$ graders in a public school in Rio de Janeiro. Inspired by the reading of Luis Dill's book Everybody against Dante which is based on real events, each student selected a real case of bullying reported in the media, created online bulletin boards with news clippings about the case and produced a text in the first person by putting him/herself in the place of the victim. This text was posted on a microblog produced with Padlet. All texts were organized in a Google Sites environment, so that they could circulate socially and fulfill real communicative goals. The results of the experiment show that the pedagogical use of ICT not only provided students' multiliteracy, but also allowed them to reflect on a real conflict - a case of bullying occurred in our school community, motivation to carry out the project - and change their attitudes in the school environment.

KEYWORDS: Multiliteracy. NICT. Authoring projects.

\section{Referências}

ALMEIDA, Maria Elizabeth Bianconcini de. Prática pedagógica e formação de professores com projetos: articulação entre conhecimentos, tecnologias e mídias. In: SECRETARIA DE EDUCAÇÃO A DISTÂNCIA, O. Integração das Tecnologias na Educação. Brasília: Ministério da Educação/SEED/TV Escola/Salto para o Futuro, 2005. p. 38-45. Disponível em: http://www.tvbrasil.org.br/saltoparaofuturo/livros.asp. Acesso em: 5 set. 2014.

CHARNEY, Davida. The impact of hypertext on processes of reading and writing. Literacy and Computers, New York, 1994. Disponível em: http://www.cwrl.utexas.edu/ charney/homepage/Articles/Charney_hypertext.pdf. Acesso em 03 nov. 2014.

COSCARELLI, Carla Viana. Leitura numa sociedade informatizada. In: MENDES, E., et al. Revisitações. Belo Horizonte: UFMG, 1999. p. 83-92.

DILL, Luís. Todos contra Dante. São Paulo: Companhia das Letras. 2008.

HERNÁNDEZ, Fernando. Entrevista: Educador espanhol explica como trabalhar a aprendizagem utilizando projetos. São Paulo: Nova Escola, 2012. Disponível em: http://www.firb.br/editora/index.php/teste/article/download/33/40. Acesso em 16 set. 2014.

HERNÁNDEZ, Fernando; VENTURA, Montserrat. Os projetos de trabalho: uma forma de organizar os conhecimentos escolares. In: HERNÁNDEZ, F.; VENTURA, $M($ (Orgs). A organização do currículo por projetos de trabalho: $O$ conhecimento é um caleidoscópio. 5ª . ed. Porto Alegre: Artmed, 1998.

$\mathrm{KOCH}$, Ingedore Grunfeld Villaça. Desvendando os segredos do texto. $2^{\mathrm{a}}$. ed. São Paulo: Cortez, 2003. 
KOMESU, Fabiana Cristina. Blogs e as práticas de escrita sobre si na internet. In: MARCUSCHI, L. A.; XAVIER, A. C (Orgs.). Hipertexto e gêneros digitais: novas formas de construção de sentido. Rio de Janeiro: Lucerna, 2005.

LEITE, Lúcia Helena Alvarez; OLIVEIRA, Maria Elisabete Penido de; MALDONATO, Mércia Diniz. Diários. Projetos de trabalho. In: BRASIL. Cadernos da TV Escola. $3^{a}$. ed. Brasília: Ministério da Educação e do Desporto, Secretaria de Educação a Distância, 1998. p. 96. ISSN 1516-148X.

MARCUSCHI, Luiz Antônio. Gêneros textuais emergentes no contexto da tecnologia digital. In: MARCUSCHI, L. A.; XAVIER, A. C (Orgs.). Hipertexto e gêneros digitais: novas formas de construção de sentido. $2^{a}$. ed. Rio de Janeiro: Lucerna, 2005.

MARTÍN-BARBERO, Jésus. Disseminação do saber e novos modos de ver/ler. In: MARTIN-BARBERO, J.; GEHMÁN, R (Orgs.). Os exercícios do ver: Hegemonia Audiovisual. São Paulo: SENAC, 2001.

NOGUEIRA, Nilbo Ribeiro. Pedagogia dos projetos: uma jornada interdisciplinar rumo ao desenvolvimento das múltiplas inteligências. $2^{a}$. ed. São Paulo: Érica, 2001.

PRADO, Maria Elisabette Brisola Brito. Pedagogia de projetos: fundamentos e implicações. In: SECRETARIA DE EDUCAÇÃ̃O A DISTÂNCIA. Integração das Tecnologias na Educação. Brasília: Ministério da Educação/SEED/TV Escola/Salto para o Futuro, 2005. p. 12-17. Disponível em: http://www.tvbrasil.org.br/saltoparaofuturo/livros.asp. Acesso em: 5 set. 2014.

ROJO, Roxane. Apresentação: Protótipos didáticos para os multiletramentos. In: ROJO, R.; MOURA, E (Orgs.). Multiletramentos na escola. São Paulo: Parábola Editorial, 2012.

Texto recebido em: 26/01/2015.

Texto aceito em: 22/07/2015. 